\title{
Problems and prospects of environmental safety of domestic agriculture
}

\author{
Irina Chupina $^{1}$, Natalia Izakova $^{2}$, and Natalia Simachkova ${ }^{2}$ \\ Russian State Vocational Pedagogical University, 620012 Yekaterinburg, Russia \\ Ural State University of Economics, 620144 Yekaterinburg, Russia
}

\begin{abstract}
The basis for the environmental safety of agricultural products should be the production of products in accordance with natural resources. In other words, it is the idea of a closed cycle, where organic livestock fertilizers are both an ecological and economic principle of production. Species diversity in the ecosystem is also an important factor in environmental safety. These are different ways of crop rotation, regulating the formation of weeds and their destruction by mechanical means, rather than by chemical means, laying hedges and habitats. These measures protect nature and do not disturb its ecological balance. Ecological agriculture aims to consider and use the soil more efficiently. For example, wetlands are better used for grassland farming rather than ploughing these sites. Also long overdue is the problem of state support of domestic farmers who produce the cleanest ecological products, more similar in composition to organic products. Guided by the principles of landscaping in agriculture, it is possible to obtain products that will not bring harm, will be high-quality and useful.
\end{abstract}

\section{Introduction}

This article deals with the self-sufficiency problems of Russia with agricultural products of domestic producers. The article deals with negative factors that hinder self-sufficiency of domestic products. The development prospects of agricultural sectors of Sverdlovsk oblast with state support are also presented. First of all, it requires state support for small forms of farming in rural areas - farms and agricultural cooperatives.

\section{Literature review}

A sufficient number of articles have been published on the topic of this article. Among them the works of D. Yedelev "Problems of providing the population of the Russian Federation with safe and high-quality food", V. Zagashvili "Food security of Russia in conditions of deterioration of relations with the EU", V. Ivanov "Food Complex: Problems of Development", E. Kovalenko "Ensuring food security of Russia on the basis of sustainable development of rural areas" and others. These works consider the problems and prospects of agricultural development of Russia, as well as its individual producers in the conditions of sanctions and environmental degradation in general. Most authors see the 
problem of getting out of this situation in the production of domestic products, where the main suppliers will be farms and smallholdings of the population.

\section{Research methodology}

The article uses methods of analysis and synthesis, analogies and factor analysis. The method of analysis and synthesis is used in the study of the socio-economic nature of agricultural development in general and Sverdlovsk oblast in particular. This method provides a combination of a comprehensive approach to the object of research. The method of analogy is used in the article to consider a particular region (Yekaterinburg) as a business entity, where the experience of consumer cooperative can be applied in all regions of the country. Factor analysis examines certain causes that have a negative impact on the environmental situation in the region and in the country as a whole.

\section{Results}

Currently, the Russian agro-industrial complex provides physical access of the population to agricultural products at a minimum consumption level compared to the countries belonging to the European Union. Agricultural production accounts for only $15-18 \%$ of the total area of the country and it is distributed very unevenly. About $40 \%$ of gross agricultural product is provided by only 14 donor regions, which are mostly industrial. But they are not yet in a position to solve the problem of full food self-sufficiency.

First of all, it requires state support for small forms of farming in rural areas - farms and agricultural cooperatives. If we look at the statistics of agricultural production, the farms, despite the fact that they do not increase in numbers, many of them are relatively large and have more than 500 hectares of arable land. Such farms typically employ only family members, and several workers are employed during the harvest period. These farms have small equipment, they use modern technologies for growing crops and use elements of modernization.

Functioning of large, medium and small forms of farming in agriculture is a prerequisite for the effective development of the agricultural sector [13].

\section{Practical significance}

The practical significance of this article is to consider scenarios for providing Russia with environmentally clean agricultural products by domestic producers. Since 2014, there has been a reorientation of both foreign and domestic trade. This is a necessary response step for the country's food security. Supporting the domestic producer in the production of their agricultural products instead of imported products is the only right way out of the current situation.

But not everything is as prosperous as it seems at first glance. Now the domestic agroindustrial complex provides physical accessibility to agricultural products of the population at a minimum consumption level in contrast to the countries belonging to the European Union. Agricultural production is carried out on only $12-13 \%$ of the entire territory of the country and is distributed extremely unevenly. Forty percent of gross agricultural product is given by only 14 donor regions, which are mainly classified as industrial ones. But, under WTO conditions, they are not yet able to solve the problem of full food self-sufficiency.

Therefore, the authors proposed the option of providing agricultural products along the example of "Spas" logistics center. Such centers in the area are only in priority. According 
to the study of the authors it is safe to say that provision of the Sverdlovsk oblast with environmentally friendly products can be done not by agricultural enterprises, but by farms and personal utility farms, where mechanization is used to the minimum amount and manual labor prevails to the maximum extent. The use of manual labor in fertilizers introduction and harvesting gives less crop losses and preserves the quality of products.

As an example of self-sufficiency of agricultural products we take Sverdlovsk oblast, which provides itself with potatoes for $132.9 \%$ and vegetables for $74 \%$. The main contribution to the provision of agricultural products is not only agricultural organizations, but also private households, which account for the cultivation of potatoes $-54 \%$ and milk production-34\%.

Sverdlovsk oblast provides itself with potatoes more at the expense of farms and private households of the population. The dynamics of potato production are stable.

Agriculture of Sverdlovsk oblast is mainly engaged in animal husbandry, where more than $60 \%$ of agricultural enterprises of the region are involved. Poultry meat accounts for a large proportion of this production. The region also develops pig breeding -about $26 \%$, cattle breeding $-14 \%$. But the figures for pig breeding have been declining in recent years. Poultry enterprises are a priority of development.

In the territory of the region a considerable share is occupied by crop production as well. It is mainly the cultivation of potatoes and cereals. In addition, the region grows legumes and vegetables in open and covered ground. Out of cereal crops, barley predominates. It accounts for an average of $15 \%$ of all acreage. Oats are grown in a smaller volume - about $4-6 \%$ of acreage. And very little of rye, millet and buckwheat is grown.

In Sverdlovsk oblast, enterprises of various forms of ownership are engaged in production of agricultural products. They are cooperatives, state farms, limited liability companies (agroindustrial firms), farms. Now there are about 420 farms in the region. And such farms produce the highest quality and environmentally friendly products.

Currently, 44 agricultural consumer cooperatives are registered in the region.

\section{Proposals and results of implementation}

In 2016, the logistics center for storage and processing of vegetables "Spas" opened in Suhoi Log. It is a consumer cooperative that includes farmers and private farms of citizens who grow crop products, harvest mushrooms and grow them, make cheeses, sausages, harvest berries. The cooperative supplies the region's food stores with crop products every day. Every day, more than 9 thousand tons of these products are shipped to stores. Thanks to modern vegetable stores, vegetables in the cooperative are stored until the next harvest. Therefore, in the shops of Sverdlovsk oblast vegetables are available all year round [2].

In the beginning, the logistics center provided sales of agricultural products from Sukholozhsky and Bogdanovich districts. But soon they were joined by peasants from Kamyshlov and Kamensk-Uralsky districts. The main criterion of the center's work is the selection of quality products. Therefore, only active enterprises work with the center, for which the quality of products comes first in their work. But not all farms are like that. Some farms are more interested in profit than in the quality of their products. Therefore, in such farms in the processing of vegetables the percentage of yield is quite high and the demand is not significant. The logistics center gives preference to those manufacturers that produce their products according to standards for grade, size, freshness and safety.

"Spas" is engaged in processing wild plants and fish. In Khanty-Mansiysk, the OJSC opened two branches for the purchase of mushrooms and berries from the population for deep freezing. This cooperative will launch its own chain of farm shops soon. The minimum trading margin is planned and the products will be fresh, high-quality and 
environmentally friendly. This will benefit small farms that do not have their own vegetable stores. Therefore, these farms are forced to sell their products only in autumn, often at the lowest price. Few of them work directly with commercial networks. The logistics center will provide such farms with more opportunities for the sale of products: signing contracts with trade networks, sorting and packaging of products, delivery of products in large and small batches by means of their own transport.

The favorable conditions for addressing the food problem include the following:

- the possibility of solving the problem of food self-sufficiency of certain regions with the necessary funds in the budget;

- the existence of an agrarian sector that can increase food self-sufficiency with the introduction of an appropriate mechanism for food interaction between the regions;

- opportunity to develop diversified types of entrepreneurship [3].

It should also be said that there are problems in the country such as:

- aggressive marketing of the promotion of goods, in which the quality of goods does not always correspond to a high level;

- various methods of manipulation of consciousness and subconsciousness of people are used mainly by means of promotions to purchase, besides, far from quality products;

- reduction of the costs of agricultural science and innovative potential development of agriculture;

- Approximately $70 \%$ of agricultural enterprises can be described as unprofitable;

- there is a decrease in fish production by $25-30 \%$;

- more than 40 million hectares of arable land have been removed from crop rotation;

- the number of cattle decreases every year [5].

It is also necessary to tighten the quality requirements of imported food, namely the content of chemical and biogenetic components that are harmful and unsafe to human health; to limit the volume and use of quotas for the import and production of genetically modified products in Russia. The support of domestic farmers is essential. In Europe, about 55 billion euros a year is allocated to support the farmers. In the United States, compensation is paid if the farmer's price can be lower than the state price. In Switzerland, farmers are subsidized by $60 \%$. In China, the agricultural tax was abolished. In Russia, very small subsidies are allocated to support farms, which often cannot cover half of the production cost. And not every farmer can afford to get a bank loan with a reasonably high interest rate [1].

If until recently the priority was state support for domestic agriculture and import substitution, now new approaches are needed, which are not only accessibility food for all, but also in improving the quality of products produced, developing domestic environmentally friendly products. This problem can be solved, first of all, by attracting farms and personal subsidiary farms to agricultural production on the domestic market, many of which have their own surplus agricultural products, and the possibility of its realization is not present. In addition, these farms grow products close to organic. Therefore, the quality of these products is much higher than that of products coming first to processing plants, and then to stores [4].

It is not the first year of talking about organic foods. At the same time, the share of the domestic market of these products is only $0.2 \%$ of the world market. And this market is developing slowly. The reason for this is high price of these products. Most consumers prefer to buy agricultural products at mid-market prices. And not every consumer is able to buy organic products, which in value is higher than other agricultural products by about 30 - 
$40 \%$. Moreover, not every consumer knows that if vegetables or fruits in a store look very attractive, it doesn't mean they are fresh and environmentally friendly products.

Thus, the problem of ensuring food security of the country includes thoughtful systemic solutions, research and implementation of an effective long-term development strategy of food self-sufficiency.

One of the pressing issues in the production of products is landscaping. The essence of landscaping is the use of natural resources to produce and preserve natural environment. In the agricultural sector, landscaping strategies are aimed at preserving varieties and breeds. Anti-erosion methods should be applied in soil treatment. There is also a need to reduce the use of pesticides and switch to natural pest control techniques. The introduction of pesticides in pest control should be abandoned, and fertilizers should be used in more biological aspect. Chemical fertilizers should be applied to the maximum permissible amount.

Previously, the main thing in agricultural activity was to obtain the highest yield of products. Currently, with extensive use of chemicalization and new technologies, it is difficult to obtain environmentally friendly products. This has a negative impact on farmland productivity. In areas where there is constant ploughing of land and chemical treatments are constantly used, there is a strong shortage of entomophages and pollinators. Because of this, plant yields decrease. Therefore, modern methods of use of scientific technologies on ecology create new opportunities in the production of agricultural products.

Now the problem is that the increase in the volume of cities and industrial enterprises removes valuable land from agricultural use. With the loss of these lands, new ones, which most often have lower fertility, need to be developed. Therefore, new approaches to the use of land resources are needed.

Currently, more than $90 \%$ of land use is done by an extensive method. The intensive method involves increasing the productivity of all areas of agricultural production with constant volume of natural resources or even reducing them. The second method is now used in all developed countries. It is also necessary to take into account the natural characteristics of land resources in different regions of the country. And based on this principle, it is necessary to consider and develop measures for amelioration, mechanization and chemicalization in each area separately, as well as the introduction of innovative methods of farming farms. In addition, additional funds are needed for the environmental component. There is little or no grant of subsidies for these needs.

\section{References}

1. I. P. Chupina, Urals agrarian herald, 8 (162), 95 (2017)

2. B.A. Voronin, I.P. Chupina, A.L. Pustuev, A.N. Semin, N.A. Potekhin, IJBR, 8(4), 1363 (2017)

3. B.A. Voronin, I.P. Chupina, V.M. Sharapova, V.V. Maslakov M.V. Fedorov, E.M. Cot, A.G. Mokronosov, The Turkish Online Journal of Design, Art and Communication, TOJDAC December Special Edition, 2102 (2017)

4. D.A. Edelev, World of agribusiness, 1, 4 (2016)

5. O. A. Alexandrova, Nikonov's readings, 14, 129 (2019)

6. I.I. Dumoulin, Russian foreign economy herald, 2, 3 (2016)

7. V. Ivanov, Economist, 3, 13 (2013)

8. V. Kiryushin, Society and Economics, 8, 92 (2013)

9. E. G. Kovalenko, Fundamental Research, 11, 224 (2017) 
10. D.A. Edelev, World of agribusiness, 1, 4 (2016)

11. V.S. Zagashvili, Russian Foreign Economic Bulletin, 8, 46 (2015)

12. J. Cotter, Agribusiness - Russia, 9, 36 (2016)

13. L. Rybak, Agribusiness - Russia, 12, 17 (2015)

14. M. Y. Tremasov, Agribusiness - Russia, 5, 73 (2016) 